\title{
CITRATE FORMATION FROM EXOGENOUS SUBSTRATES BY WASHED HUMAN SPERMATOZOA
}

\author{
R. N. PETERSON AND M. FREUND \\ Laboratory of Reproductive Pharmacology of the Departments of Pharmacology \\ and of Obstetrics and Gynecology, New Tork Medical College, \\ Valhalla, New York 10595, U.S.A.
}

(Received 8th Fune 1973)

\begin{abstract}
Summary. In the presence of glucose, respiration and the levels of citric acid cycle intermediates in washed human spermatozoa are low. Citrate levels are not markedly increased by pyruvate, lactate or acetate, nor do these compounds increase respiration. Succinate, which is oxidized at high rates, increases citrate levels about fourfold; however, the increased respiration is attributed to the succinate-fumarate conversion alone and not to a general stimulation of the citric acid cycle. The addition of succinate, malate, or fumarate to sperm suspensions containing pyruvate increases citrate levels 50 - to 100 -fold, markedly stimulates $\alpha$-ketoglutarate formation, decreases glycolysis and almost doubles the rate of pyruvate utilization. The increased rates of the synthesis of citrate and other intermediates of the citric acid cycle are not accompanied by increased rates of respiration. These data argue for the presence of a powerful pyruvate dismutation pathway in human spermatozoa in which lactic dehydrogenase competes successfully for the reducing equivalents generated by pyruvate oxidation and argues against the idea that oxidation in spermatozoa is limited by substrate entry into the citric acid cycle.
\end{abstract}

\section{INTRODUCTION}

Human spermatozoa respire at low rates whether suspended in seminal plasma or in simple salt solutions (MacLeod, 1941; Terner, 1960; Peterson \& Freund, $1968,1970)$. The addition of succinate to washed spermatozoa, however, markedly stimulates respiration (Hamner \& Williams, 1964). This suggests that at least a portion of the respiratory chain in these cells is capable of supporting a high rate of electron transfer. In an attempt to obtain more information about the mechanisms limiting the oxidation of pyridine nucleotide-linked substrates, the effects of a variety of potentially oxidizable substrates on intracellular levels of citrate and other Krebs' cycle intermediates were determined. Our results eliminate several possible causes for the low rates of respiration by human spermatozoa, including a limitation imposed by a low rate of substrate entry into the Krebs' cycle. 


\section{MATERIALS AND METHODS}

Semen specimens obtained from normal donors were pooled before use. The methods used for obtaining sperm motility ratings and cell counts and the procedure used for preparing plasma-free suspensions have been described previously (Peterson \& Freund, 1968). Washed spermatozoa were resuspended in a medium containing tris-buffered salts that had the following composition: $0.118 \mathrm{~m}$-sodium chloride; $0.03 \mathrm{~m}$-tris (hydroxymethyl) aminomethane (tris)chloride; $0.003 \mathrm{M}$-dipotassium hydrogen phosphate; $0.005 \mathrm{M}$-magnesium chloride; $0.0001 \mathrm{~m}$-disodium EDTA and $0.0015 \mathrm{~m}$-glucose. The $\mathrm{pH}$ was adjusted to 7.4 at $37^{\circ} \mathrm{C}$.

Aliquots $(3.0 \mathrm{ml})$ of the washed sperm suspensions containing between $2 \times 10^{8}$ and $4 \times 10^{8}$ cells were incubated with shaking in a Dubnoff shaker with air or nitrogen as the gas phase for 20 to $40 \mathrm{~min}$ at $37^{\circ} \mathrm{C}$. Metabolism was stopped by the injection of $1 \mathrm{ml}$ cold $30 \%$ perchloric acid. Glycolytic intermediates were extracted and assayed by methods described in an earlier report (Peterson \& Freund, 1971). Citric acid cycle intermediates were assayed by fluorimetric procedures described by Williamson \& Corkey (1969). Particular assays employed the following enzyme systems coupled to the reduction or oxidation of pyridine nucleotides: citrate-citrate lyase and malate dehydrogenase; $\alpha$-ketoglutarate-glutamate dehydrogenase; succinate-succinic thiokinase, pyruvate kinase and lactic dehydrogenase; malate-malate dehydrogenase; fumarate -fumarase and malate dehydrogenase. Estimates of intracellular citrate were obtained by subtracting the amount of extracellular citrate that was retained in the supernatant fluid after the washing procedure from the total amount of citrate found in extracts. This correction was not necessary for the other intermediates assayed.

In experiments where only glucose uptake and lactic acid formation were of interest, metabolism was stopped by boiling aliquots of cell suspensions for 90 sec. The boiled suspension was then cooled and centrifuged. Glucose and lactic acid were determined in triplicate in all experiments. Because of the low concentrations of other intermediates, large volumes of extract were needed and single or, at most, duplicate assays were possible. Most experiments were, therefore, repeated at least three times and the results are presented as the average \pm the standard error (S.E.).

Oxygen uptake was measured polarographically using a Beckman Oxygen Analyzer and a Clark-Type electrode. The electrode was standardized by measuring the amount of oxygen consumed when a known amount of glucose was added to a solution of glucose oxidase (glucostat special, Worthington Biochemical Company, 1 vial dissolved in $10 \mathrm{ml}$ buffer). Homovanillic acid was added $(1 \mathrm{mg} / \mathrm{ml})$ to the enzyme solution in order to consume the peroxide generated during the course of glucose oxidation. A description of the electrode vessel used in these studies is given in an earlier report (Peterson \& Freund, 1970).

Sigma grade or Baker reagent grade chemicals were used. Purified enzymes were purchased from the Boehringer-Mannheim Company. 


\section{RESULTS AND INTERPRETATION}

Table 1 shows the intracellular levels of glycolytic and citric acid cycle intermediates obtained after incubating washed spermatozoa in the buffered glucose-salts medium. As discussed in an earlier report (Peterson \& Freund, 1971), glycolytic intermediates accumulate at the phosphofructokinase and glyceraldehyde phosphate dehydrogenase steps and it is these steps that appear to control the rate of glycolysis. Intermediates distal to these steps and the intermediates of the citric acid cycle are present in comparatively lower concentrations. Under these conditions, oxygen consumption is low.

In view of the fact that virtually all the glucose that was taken up by these cells appeared in the medium as lactic acid, it was possible that the low levels of the citric acid cycle intermediates and the low respiratory rate were due to

Table 1. Levels of glycolytic and citric acid intermediates in washed human spermatozoa suspended in glucose-salts medium

\begin{tabular}{|c|c|}
\hline Intermediate & $\begin{array}{c}\text { Intracellular concentration } \\
\left(\text { nmol } / 10^{8} \text { spermatozoa }\right)\end{array}$ \\
\hline $\begin{array}{l}\text { Hexose monophosphate } \\
\text { Triose phosphate+fructose diphosphate } \\
\text { 3-Phosphoglycerate } \\
\text { Phosphoenol pyruvate }\end{array}$ & $\begin{array}{l}2 \cdot 0 \pm 0.2(18) \\
10 \cdot 1 \pm 0.8(9) \\
1 \cdot 1 \pm 0 \cdot 2(6) \\
0 \cdot 6 \pm 0.1(4)\end{array}$ \\
\hline $\begin{array}{l}\text { Citrate } \\
\alpha \text {-Ketoglutarate } \\
\text { Malate } \\
\text { Succinate }\end{array}$ & $\begin{array}{l}0.9 \pm 0.2(4) \\
0.4 \pm 0.2(3) \\
0.5 \pm 0.1 \text { (3) } \\
0.9 \pm 0.1\end{array}$ \\
\hline
\end{tabular}

Spermatozoa were incubated for $20 \mathrm{~min}$ at $37^{\circ} \mathrm{G}$ in the tris-buffered medium containing glucose. The number of experiments involved in a particular experiment is given in parentheses. Values are means $\pm S . E$.

the inability of mitochondrial pyruvate dehydrogenase to compete effectively with lactic dehydrogenase for the pyruvate generated during glycolysis. However, when the oxidizable substrates pyruvate, lactate, or acetate were added in high concentrations to the sperm suspensions, there was no measureable increase in sperm respiration nor any statistically significant increases in intracellular citrate levels.

With the single exception of succinate, Krebs' cycle intermediates added exogenously also did not induce a respiratory response. Succinate, however, induced about a fivefold increase in respiration, raising the rate to a level that is similar to that of species of mammalian spermatozoa with highly active oxidative metabolism such as the ram, bull and guinea-pig.

Some of the changes in the metabolic characteristics of human spermatozoa after the addition of succinate are shown in Table 2 . There was only a slight decrease in the glycolytic rate in the presence of succinate despite the very large increase in respiration. Citrate levels increased three- to fourfold but there was no significant change in the level of $\alpha$-ketoglutarate; the rate of malate formation was very high and, in this instance, was greater than the rate of lactic acid 
production from glucose. A comparison of the increment in oxygen uptake induced by succinate with the rate of malate formation indicates that most if not all of the change in oxygen consumption can be accounted for by the succinate-fumarate conversion alone rather than by a general stimulation of Krebs' cycle turnover. This is also indicated by the observation that rotenone, which inhibits pyridine nucleotide-linked oxidations, blocks endogenous respiration but has little effect on succinate-supported respiration.

Table 2. Effect of exogenous succinate on the metabolism of human spermatozoa and the level of tricarboxylic acid cycle intermediates

\begin{tabular}{|c|c|c|}
\hline Intermediate & Glucose $(1.5 \mathrm{~mm})$ & Glucose + succinate $(5 \mathrm{mM})$ \\
\hline $\begin{array}{l}\text { Citrate } \\
\alpha-\text { Ketoglutarate } \\
\text { Malate }\end{array}$ & \multicolumn{2}{|c|}{ 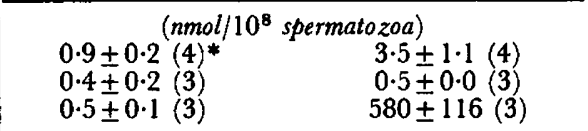 } \\
\hline $\begin{array}{l}\text { Glucose used } \\
\text { Lactate formed } \\
\text { Malate formed }\end{array}$ & \multicolumn{2}{|c|}{ 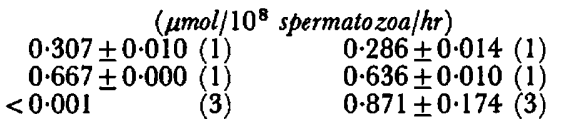 } \\
\hline Oxygen uptake & \multicolumn{2}{|c|}{ 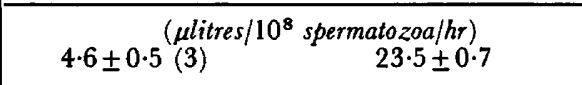 } \\
\hline
\end{tabular}

The number of experiments involved is given in parentheses. Where three or more experiments are indicated, results are mean values \pm standard error; the values for single experiments are the average \pm standard deviation of assays done in triplicate.

Table 3. Effect of combinations of exogenous substrates on citrate and $\alpha$-ketoglutarate levels in washed human spermatozoa

\begin{tabular}{l|cc}
\hline \multicolumn{1}{c|}{ Addition* } & \multicolumn{2}{|c}{ Citrate } \\
& \multicolumn{2}{|c}{$\begin{array}{c}\alpha-\text { Ketoglutarate } \\
(\text { nmol/108 }\end{array}$} \\
\cline { 2 - 3 } Spermatozoa)
\end{tabular}

The number of experiments involved is given in parentheses.

* Glucose $1.5 \mathrm{~mm}$, other additions $5 \mathrm{~mm}$.

When succinate and pyruvate were given together, as shown in Table 3, there was a large increase in citrate synthesis and citrate accumulated in the medium. This was accompanied by nearly an eightfold increase in the level of $\alpha$-ketoglutarate. A high rate of citrate synthesis also occurred when malate or fumarate were added in combination with pyruvate or in combination with 
acetylcarnitine. These substrate combinations also increased $\alpha$-ketoglutarate levels. Citrate synthesis, however, was significantly lower when lactate was substituted for pyruvate while the substitution of acetate failed to induce any increase in citrate formation.

Substrate combinations which increased citrate levels had feedback effects on the levels of glycolytic intermediates as shown in Table 4. Glucose utilization was reduced significantly in the presence of succinate. This was probably a result of citrate accumulation and inhibition of phosphofructokinase since there was a marked increase in the glucose-6-phosphate and fructose-6-phosphate levels without significant changes in the ATP/ADP ratio. This was also suggested by the observation that similar feedback effects occurred when fumarate, which did not induce a respiratory increase, was substituted for succinate.

Table 4. Effect of stimulants of citrate synthesis on glycolysis by human spermatozoa and on glycolytic intermediates

\begin{tabular}{|c|c|c|c|c|}
\hline Intermediate & Pyruvate & $\begin{array}{c}\text { Pyruvate } \\
+ \\
\text { succinate }\end{array}$ & Pyruvate & $\begin{array}{c}\text { Pyruvate } \\
+ \\
\text { fumarate }\end{array}$ \\
\hline $\begin{array}{l}\text { Fructose-6-phosphate } \\
\text { Glucose-6-phosphate }\end{array}$ & $\begin{array}{l}\left(n m o l / 10^{8}\right. \\
0.49 \pm 0.01 \\
1 \cdot 75 \pm 0.15\end{array}$ & $\begin{array}{c}\text { spermatozoa)* } \\
1.02 \pm 0.14 \\
2.85 \pm 0.30\end{array}$ & $\begin{array}{l}\left(n m o l / 10^{8} s p\right. \\
0 \cdot 34 \pm 0 \cdot 01 \\
1 \cdot 18 \pm 0 \cdot 15\end{array}$ & $\begin{array}{c}\text { ermatozoa })^{*} \\
0.65 \pm 0.21 \\
1.81 \pm 0.11\end{array}$ \\
\hline $\begin{array}{l}\text { Fructose diphosphate } \\
\text { Triose phosphate }\end{array}$ & $\begin{array}{l}1 \cdot 29 \pm 0 \cdot 16 \\
3 \cdot 06 \pm 0 \cdot 12\end{array}$ & $\begin{array}{l}1 \cdot 12 \pm 0.17 \\
3 \cdot 01 \pm 0.45\end{array}$ & $\begin{array}{l}1 \cdot 51 \pm 0 \cdot 10 \\
4 \cdot 03 \pm 0.53\end{array}$ & $\begin{array}{l}1.41 \pm 0.23 \\
3.62 \pm 0.37\end{array}$ \\
\hline $\begin{array}{l}\text { ATP } \\
\text { ADP }\end{array}$ & $\begin{array}{r}15 \cdot 0 \pm 2 \cdot 4 \\
9 \cdot 5 \pm 1 \cdot 1\end{array}$ & $\begin{array}{r}14 \cdot 6 \pm 2 \cdot 2 \\
9 \cdot 5 \pm 1 \cdot 5\end{array}$ & $\begin{array}{l}16 \cdot 0 \pm 1 \cdot 1 \\
10 \cdot 3(2) \dagger\end{array}$ & $\begin{array}{l}15 \cdot 7 \pm 1 \cdot 5 \\
10 \cdot 4(2) \dagger\end{array}$ \\
\hline $\begin{array}{l}\text { Glucose used } \\
\text { Lactate formed } \\
\text { Pyruvate used }\end{array}$ & $\begin{array}{c}\left(\mu \mathrm{mol} / 10^{8}\right. \\
0.659 \pm 0.053 \\
1.417 \pm 0.010 \\
0.484 \pm 0.020\end{array}$ & $\begin{array}{r}\text { bermatozoa/hr) } \\
0.543 \pm 0.000 \\
1.719 \pm 0.010 \\
0.906 \pm 0.035\end{array}$ & $\begin{array}{c}\left(\mu \mathrm{mol} / 10^{8} \text { spe }\right. \\
0.475 \pm 0.017 \\
1.190 \pm 0.032 \\
0.335 \pm 0.099\end{array}$ & $\begin{array}{l}\text { rmatozoa } / \mathrm{hr})^{+} \\
0.440 \pm 0.039 \\
1.450 \pm 0.006 \\
0.671 \pm 0.010\end{array}$ \\
\hline
\end{tabular}

\footnotetext{
* Mean \pm S.E. of three experiments.

$\dagger$ Mean of two experiments.

$\ddagger$ Mean \pm S.D. of one experiment.
}

It is of further interest that the high rate of succinate oxidation did not induce an appreciable change in the ATP/ADP ratio. This is conceivably due to a loose coupling of oxidation to phosphorylation in these cells as we have suggested previously (Peterson \& Freund, 1970).

Despite the fall in glucose utilization, lactate production increased substantially when succinate or fumarate and pyruvate were added in combination. This increase was almost entirely due to increased pyruvate utilization and conversion to lactate. The conversion exceeded what would have been expected from a stoichiometric pyruvate dismutation in which $2 \mathrm{~mol}$ pyruvate form $1 \mathrm{~mol}$ lactate and $1 \mathrm{~mol}$ acetyl CoA. This suggests that the extra reducing equivalents generated at the malate-oxalate conversion and perhaps at other mitochondrial redox sites, as well as those generated by pyruvate dehydrogenase, are reoxidized by lactic dehydrogenase and that very little is oxidized by mitochondrial pyridine nucleotide dehydrogenase.

Judging from the amount of citrate formed in the presence of pyruvate and 
fumarate, a minimum increase in oxygen uptake of about $5 \mu$ litres $/ 10^{8}$ spermatozoa/hr would occur if all the electrons generated at malate dehydrogenase and pyruvate dehydrogenase were passed down the respiratory chain. However, we were not able to detect any measurable increase in sperm respiration in the presence of pyruvate and fumarate or, for that matter, in the presence of any of the substrate combinations which induced high rates of citrate synthesis. Thus it appears, at least in the presence of pyruvate, that most of the reducing equivalents generated during citrate synthesis are channelled back to lactic dehydrogenase for the further reduction of pyruvate. This conclusion is strengthened by the results of the experiments carried out under anaerobic conditions that are included in Table 3. Here it is shown that the conversion of fumarate plus pyruvate to citrate and $\alpha$-ketoglutarate proceeded at almost the same high rate whether or not oxygen was present. Since other experiments have shown that pyruvate conversion to lactate under anaerobic conditions is also stimulated by fumarate, it is apparent that lactic dehydrogenase is a powerful competitor for the electrons generated during Krebs' cycle reactions under both anaerobic and aerobic conditions.

\section{DISCUSSION}

The results of these experiments permit several conclusions concerning the control of oxidative metabolism in human spermatozoa. Since citrate and other Krebs' cycle intermediates are readily formed from pyruvate, provided a source of oxaloacetate is present, other factors such as the availability of coenzyme A, and the activity of pyruvate dehydrogenase or citrate synthetase probably do not ordinarily limit the entrance of most substrates into the TCA cycle and the oxidation rate. In washed cells, and perhaps in semen as well, entrance into the cycle appears to be limited merely by the availability of oxaloacetate. The conversion of acetate to citrate, however, was not increased in the presence of substrates that increase oxaloacetate levels and apparently the rate of formation of acetylcoenzyme-A from acetate limits entry into the cycle in this instance. This interpretation is in accord with the results of Terner (1960) who found that acetate was oxidized by human spermatozoa at much lower rates than either glucose or pyruvate.

Although an increased rate of citrate formation may increase the rate of oxidation of a particular substrate, the total rate of respiration was not increased by stimulation in citrate synthesis and other factors obviously dominate the control of the oxidation of pyridine nucleotide-linked substrates. The high rate of succinate oxidation indicates that the major portion of the respiratory chain is capable of supporting a high rate of electron transfer. Moreover, the generation of high levels of TCA cycle intermediates from exogenous precursors suggests that most of Krebs' cycle enzymes are probably present in more than adequate concentrations to handle the substrate loads they ordinarily encounter. Oxidation may, therefore, be limited by the catalytic capacity of mitochondrial pyridine nucleotide dehydrogenase or by some form of stringent cofactor control.

Finally, as regards the absence of an appreciable Pasteur effect in these 
cells, it is becoming increasingly evident that several metabolic pecularities contribute to this effect. First, as we have mentioned in previous work, $\alpha$-glycerophosphate dehydrogenase activity is low (Peterson \& Freund, 1971). This tends to increase the NADH available to lactic dehydrogenase for pyruvate reduction and would lower the acetyl CoA available for mitochondrial oxidation. Second, high ATP/ADP ratios are not generated in these cells, perhaps due to a loose coupling of respiration to phosphorylation. This would tend to lessen feedback inhibition of glycolysis at several points in the glycolytic sequence. In addition, as some of the evidence presented in this report suggests, citrate synthesis in these cells may not be high enough to exert a significant feedback effect on the glycolytic apparatus.

\section{ACKNOWLEDGMENTS}

The authors gratefully acknowledge the technical assistance of Miss Cecil Miller and Miss Ollie Brown. Succinic thiokinase was the kind gift of Dr William A. Bridger of the University of Alberta.

\section{REFERENCES}

Hamner, G. E. \& Williams, W. L. (1964) Identification of sperm stimulating factor of rabbit oviduct fluid. Proc. Soc. exp. Biol. Med. 117, 240.

MacLeod, J. (1941) The metabolism of human spermatozoa. Am. F. Physiol. 132, 193.

Peterson, R. N. \& Freund, M. (1968) An evaluation of the respiratory capacity of human spermatozoa. F. Reprod. Fert. 17, 357.

Peterson, R. N. \& Freund, M. (1970) ATP synthesis and oxidative metabolism in human spermatozoa. Biol. Reprod. 3, 47.

Peterson, R. N. \& Freund, M. (1971) Glycolysis by human spermatozoa: levels of glycolytic intermediates. Biol. Reprod. 5, 221.

Terner, C. (1960) Oxidation of exogenous substrate by isolated human spermatozoa. Am. F. Physiol. 198, 48.

Williamson, J. R. \& CoRkey, B. A. (1969) Assays of intermediates of the citric acid cycle and related compounds by fluorometric enzyme methods. In Methods in Enzymology, Vol. XIII, p. 434 ff. Ed. J. M. Lowenstein. Academic Press, New York. 